\title{
ROOTED COSMOPOLITAN IDENTITY \\ AND INTERNALIZED HOMOPHOBIA \\ IN FARZANA DOCTOR'S \\ STEALING NASREEN
}

Brno Studies in English

Volume 46, No. 2, 2020

ISSN 0524-6881 | e-ISSN 1805-0867

https://doi.org/10.5817/BSE2020-2-10

\section{Shobana Jeyasingam, Manimangai MaNi, Rosli Talif and MOHAMMAD EWAN AWANG}

\begin{abstract}
Rooted cosmopolitanism is a concept espoused by renowned philosopher Kwame Anthony Appiah that proposes individuals adhere to two inter-related strands to construct a rooted cosmopolitan identity. The first strand advocates that one puts faith in the equal acceptance and fair treatment of all people regardless of race, gender, or affiliation while the second strand denotes that one should stay rooted in one's own culture and familial values. As a marginalized community, the LGBTQ face various struggles which jeopardize their ability to construct a rooted cosmopolitan identity. Thus, Farzana Doctor's Stealing Nasreen will be examined to discover how an Indian migrant character struggles to construct a rooted cosmopolitan identity in her new home country, Canada, as a result of having internalized homophobia. Internalized homophobia is developed when societal stigma, family values and upbringing that demoralize the LGBTQ are redirected internally resulting in insidious inner conflicts.
\end{abstract}

\section{Key words}

Rooted cosmopolitanism; rooted cosmopolitan identity; internalized homophobia; Indian diaspora; migrant fiction

\section{Introduction}

Contemporary cosmopolitans adhere to the idea that each individual has worldwide stature as a definitive unit of good concern and is thus liable for equivalent regard and acceptance regardless of what one's citizenship status or different affiliations happen to be. Cosmopolitanism is a concept that can be traced to its genesis from the Grecian Diogenes Laertius who proclaimed himself to be "a citizen of the world" i.e. a cosmopolitan. The concept is an espousal towards values of equality, equity, acceptance, and respect of individualities which denotes the importance of being a borderless world not just from an economic or political standpoint but also through a cultural and communal viewpoint. Cosmopolitans are people who do not prescribe to being defined by the trappings of geographical locations, racial and religious affiliations or cultural conventions. Cosmopolitans are individuals living in a shared world who subscribe to the idea that as members of a borderless world, every individual bears the obligation of embracing pluralistic qualities that give importance to all individuals regardless 
of their own inclinations, station, statement of faith, ethnicity, sexual direction, and so on.

Subsequently, American philosopher Martha Nussbaum prescribes to the notion of recognizing all of humankind as of equal importance and doing away with parochial roots. As a proponent of strict ethical cosmopolitanism, she advocates the complete negation of cultural affiliations in being cosmopolitan. At the crux of Nussbaum's arguments is the notion that one's patriotism and cultural identifications are not a prerequisite for being a cosmopolitan. (Nussbaum 2010: 160). In fact, she proposes that as the world shrinks its borders and mobility becomes second nature, a cosmopolitan should not subscribe to any cultural affiliations of the motherland and only prescribe to the love for humanity as a whole. Such inclinations are not applicable to many cultures such as the Indian diaspora where cultural affiliations are not simply turned away.

In contrast with Nussbaum's notions, Appiah, the Ghanaian-British scholar proffers an alternative approach to the concept. A prominent and esteemed proponent of cosmopolitanism is Kwame Anthony Appiah, who subscribes to the concept of being a rooted cosmopolitan. In 2006, Appiah penned a book entitled Cosmopolitanism: Ethics is a World of Strangers where he drew from his past works and personal experiences to delineate the idea of rooted cosmopolitanism and its pertinence to present times cosmopolitan goals and standpoints. Appiah explicates that rooted cosmopolitanism furnishes individuals with the chance to influence each other's lives like never before now more than previously. Subsequently, he imports on how one can influence the lives of others while also gaining from them. This notion that is put forth by Appiah, whereby cross-cultural conversations and pluralistic values are upheld, is the strength of his cosmopolitan perspective which is the main reason for this paper's interest in examining the rooted cosmopolitan perspective as a desirable standard for social identity.

Appiah's rooted cosmopolitanism connects two inter-related strands. The first is the onus that we are obliged and share mutual responsibility to those who are beyond our own close relatives, kinsmen or affiliates. A cosmopolitan is a member of a global village and it proposes belonging to the human community and upholding universal values of concern while also appreciating the lives, practices, and convictions of others and accepting and learning from differences across multicultural communities. The second strand denotes the vocation to remain rooted to one's own culture and beliefs while being involved in cross-cultural conversations. To develop a rooted cosmopolitan identity, one should be immersed in both strands and embed an identity within that reflects an avocation to both strands.

Preceding his 2006 book on rooted cosmopolitanism, Appiah discusses the ideas behind his cosmopolitan perspective in his work Cosmopolitan Patriot (1997). In his discussions, he denotes that:

In a world of cosmopolitan patriots, people would accept the citizen's responsibility to nurture the culture and the politics of their homes. Many would, no doubt, spend their lives in the places that shaped them; and that is one of the reasons local cultural practices would be sustained and trans- 
mitted. But many would move; and that would mean that cultural practices would travel also (as they have always travelled). The result would be a world in which each local form of human life was the result of long-term and persistent processes of cultural hybridization: a world, in that respect, much like the world we live in now. (Appiah 1997: 619)

Appiah's projection of how the world should be and somewhat has been employs the idea that all cultures are formed through the amalgamation of diasporas mingling and cross-cultural conversations. Therefore, the significance to the present paper is reflected through examining an Indian migrant character's identity that is very much immersed in her cultural affiliations of the motherland but also weaving through the experiences of a new culture that has been sought after for upward mobility.

In literary studies, cosmopolitanism is a concept that is highly significant in its ability to highlight human experiences and relationships not only from a personal perspective but also within a societal framework. Kymlicka and Walker (2012: 3) argue that "today's cosmopolitanism must be a postcolonial cosmopolitanism that is divorced from ideas of either cultural homogenization or political unification, accepting of cultural diversity and the rights of the world's people to a local autonomy. And it is in this context that ideas of rooted cosmopolitanism have emerged." They further highlight that as people have the need "to build bonds of solidarity and political dialogues across ethnic and linguistic lines, they have never felt that moral obligations and political relations can only be made with people 'just like them', therefore widening the scope for the "cosmopolitan potential in terms of citizenship and solidarity" (Kymlicka and Walker 2012: 13). However, scholars such as Thobani (2007) and Razack (2004) argue that the multiculturalism clause adopted can be described as a shroud that conceals White supremacy over the racialized Other by adopting the identity of being open cosmopolites. Nonetheless, it is the idea that "mediating this relationship of equanimity and inclusiveness as opposed to cultural supremacism and pushing it from one direction to another" (Kymlicka and Walker 2012: 17) that posits the rooted cosmopolitan argument as salient and highly significant to diasporic experiences.

In order to discuss the scenario of the Indian migrant developing a rooted cosmopolitan identity, Canadian author, Farzana Doctor's novel Stealing Nasreen will provide the backdrop for the discussion. Appiah's two strands of rooted cosmopolitan will be applied to demonstrate the rooted cosmopolitan identity developing in the Indian migrant characters. Nonetheless, one particular character in the novel displays an inability to develop a rooted cosmopolitan identity. This character is an LGBTQ character, Salma, who is a lesbian. Salma displays manifestations of internalized homophobia through horizontal oppression, secrecy and concealment. These manifestations are seen to be the result of her culture, familial values and upbringing. This problem that plagues her has resulted in her inability to embrace both strands of Appiah's rooted cosmopolitanism whereby having internalized homophobia which stems from her values and upbringing has ensued the inability to accept her own true identity and others of the LGBTQ subculture. 


\section{Rooted cosmopolitan identity in Stealing Nasreen}

Stealing Nasreen (2007) by Farzana Doctor is a novel about a married couple, Shaffiq, an accountant, and Salma, a teacher, who migrate from their native India to Toronto in Canada in search of mobility and a better life for their daughters. Salma is a lesbian but has repressed her LGBTQ identity for years due to her knowledge that such an inclination would not be accepted by her family. The story and her sexual preference unfold upon her meeting Nasreen, a second generation Indo-Canadian, whom starts taking native language classes with Salma. Nasreen is a lesbian who is open and real about her sexual inclinations. Meeting Nasreen results in Salma recollecting her past from which we are able to garner that she is indeed a lesbian herself. However, before Salma's inclinations are discussed further, it is vital to first discuss the construction of a rooted cosmopolitan identity among the migrant characters in Stealing Nasreen. The migrant characters analysed would be Shaffiq, his friend Ravi, and Salma herself.

Migration is a rooted cosmopolitan tenet as delineated by Appiah (1997) whereby the mobility of people results in intermingling and interconnecting of divergent cultures. The contentions of Appiah (1997: 618-619) about migration are evident in the excerpt below:

The cosmopolitan patriot can entertain the possibility of a world in which everyone is a rooted cosmopolitan, attached to a home of one's own, with its own cultural particularities, but taking pleasure from the presence of other, different places that are home to other, different people. The cosmopolitan also imagines that in such a world not everyone will find it best to stay in their natal patria, so that the circulation of people among different localities will involve not only cultural tourism (which the cosmopolitan admits to enjoying) but migration, nomadism, diaspora. In the past, these processes have too often been the result of forces we should deplore; the old migrants were often refugees, and older diasporas often began in an involuntary exile. But what can be hateful, if coerced, can be celebrated when it flows from the free decisions of individuals or of groups.

Being migrant characters, Salma, Shaffiq, and Ravi have exposed themselves to the intermingling of cultures in the host country of Canada. The notion of mobilizing one's self and family in itself is rooted cosmopolitan in nature. Therefore, these migrant characters inadvertently subscribe to a rooted cosmopolitan identity by recognizing the importance of migration and upward mobility.

Another key tenet of Appiah's rooted cosmopolitanism is having cross-cultural conversations whereby the meeting of different cultures can be celebrated and encouraged. In doing so, the rooted cosmopolitan society of the host country is strongly represented. Robert Maciel (2014: iv) discusses Appiah's rooted cosmopolitanism and prescribes an alternative perspective to rooted cosmopolitanism whereby he argues that in order to be successful, rooted cosmopolitanism should be conceived of as complex and open-ended. The complexity being the idea that it incorporates moral, political, and cultural variants of cosmopolitanism, and 
the open-endedness being that it is subject to continual re-negotiation over time depending "upon changing current norms around state sovereignty and establishing global governance." Maciel echoes Appiah's ideas that being a rooted cosmopolitan entails a renegotiation of cultural norms as societies in general and people evolve. These ideas entail changing beliefs and understanding of others through cross-cultural relationships.

In Stealing Nasreen, there is also acceptance of cross-cultural connections such as Ravi's with his Anglo-Canadian girlfriend. In the excerpt below, Shaffiq speaks to his friend, Ravi about his relationship with Angie:

Shaffiq nods, visualizing Angie with her blue eyes spooning Ravi broth. "You think it can work out with a Canadian? In the long run? They are so different from us, Ravi."

"Well, I didn't think so at first. But, love is love, right? Why should it matter about our differences?"

"We can overcome our differences."

"But those are big differences. Don't underestimate them. You're talking culture, and religion on top, too." "That stuff doesn't matter to us. That stuff doesn't matter in Canada.

"I mean, look at you and me," he says pointing to Shaffiq and then back to himself. "Would we ever have been friends in India? A Hindu tailor and a Muslim accountant?

"Well I guess things are a little different over there..." (Doctor 2007: 115)

The excerpt above achieves two important ideas about cross-cultural conversations that represent a rooted cosmopolitan society. First and foremost, from the perspective of the Indian diaspora, the characters are first able to inter-mingle with people of other faiths and ethnicities even to the extent of entering marital unions and having families. Concurrently, the two men also highlight the disparity they faced for hailing from different religious backgrounds in their own motherland. However, migrating to Canada has opened up avenues for relationships and friendships with not only the Westerners per se but even among Indian diasporic communities that were previously bound by highly discriminative societal conventions of the motherland that divide communities based on caste, creed, or religious affiliations. These cross-cultural conversations are channels and conduits of cosmopolitan ideals that embrace pluralistic values.

In a similar vein, another cosmopolitan tenet as delineated by Appiah (2006) is accepting differences between people and communities regardless of backgrounds, caste, creed, ethnicity, or affiliations. This tenet also encourages the need for individuals and their communities to exercise acceptance and be devoid of prejudice against one another. In the excerpt below, Shaffiq contemplates on the convivial, cosmopolitan space in his new country:

Of course, religion caused problems for him. No pay raises, no promotions for the minority man in India. But those subtleties don't seem to matter here, Shaffiq thinks. (Doctor 2007: 25) 
Shaffiq's contemplations are key in understanding the cosmopolitan climate of the host country. Whereas his religious affiliation had clustered him into the minority pool in his motherland, the cosmopolitan host country has presented no such qualms for him.

The excerpts garnered about Shaffiq and Ravi can be clear indications of their intermingling, acceptance of other cultures, conviviality with others, and immersion in cross-cultural relationships. Both characters also show no apparent disdain for their own cultural affiliations while accepting other cultures in their new circumstances. Therefore, both characters can be seen as developing a rooted cosmopolitan identity. Concurrently, Salma too displays an acceptance of the new culture when she discusses the future of her children in Canada.

"Maybe he'll [Ravi] be able to weather his mother's disapproval so far away from home. Things are different here. No one cares if you marry in the same religion or culture, or even if you marry at all. Just look at my two students. Independent women in their thirties. They can do anything they want. That's how it will be for our girls." (Doctor 2007: 267)

Salma is clearly inclined to believe that Canada is more inclusive and therefore more appropriate for them to bring up their daughters. The inclusivity and acceptance shown for people regardless of race or backgrounds is vital in imbibing such values through a rooted cosmopolitan identity.

Subsequently, an important aspect of Appiah's rooted cosmopolitanism is staying rooted to one's own culture and beliefs which can include family values and also religious beliefs that are brought from the native country. Concomitantly, Salma, found a stronger connection to her Muslim community and her religion due to her migration to Canada. Having been non-religious for the longest of time, upon migrating to Canada, she begins to seek the connections of her community and the congregations of her clan by attending prayers at the nearby mosque, much to her own husband's chagrin. Salma even replies to Shaffiq that she is going to "keep an open mind" when he gesticulates that she never had anything "in common with those ridah ladies" referring to overtly pious Muslim women (Doctor 2007: 52). Remaining rooted in one's own culture and even religion is a strong indicator of a rooted cosmopolitan identity.

From the excerpts and discussions above, it is evident that the characters have begun to embrace a rooted cosmopolitan identity. But, the discussion now begins to centre on Salma. Although Salma can be seen to become more affiliated with her religious culture, the paper seeks to expound that there is an element of hypocrisy in Salma's rootedness to her beliefs and culture. While she is herself a lesbian, affiliations to her culture may fulfil her imbibing of Appiah's second strand of remaining true to one's own culture. It does not however display her ability to be accepting of differences in affiliations when she has completely negated her own affiliation to an alternate sexual preference nor has she shown true acceptance for other people who are gay. A rooted cosmopolitan identity is based on the understanding that the society of the host country embraces cosmopolitan values that are devoid of prejudice and biases and that upholds universal 
values of acceptance, equal and just treatment, as well fairness to all individuals and subcultures in a society. Therein lies the problem that Salma encounters whereby she cannot develop a rooted cosmopolitan identity as she fails to accept alternate sexual preference as a valid affiliation even for herself. This inability largely stems from a condition that she has developed as a gay person herself which is called internalized homophobia.

\section{Internalized homophobia, family values and upbringing as challenges to constructing a rooted cosmopolitan identity}

Internalized homophobia is a psychological term derived from the works of Meyer and Dean (1998: 161). They iterate that "internalized homophobia is the gay person's direction of negative social attitudes toward the self, leading to a devaluation of the self and resultant internal conflicts and poor self-regard." What this entails is that societal stigma against the LGBTQ is redirected internally causing a gay person to experience internalized homophobia and its manifestations.

One key manifestation of internalized homophobia discussed and highlighted by Meyer and Dean (1998) is horizontal oppression. This manifestation occurs when a gay person themselves develop discomfort, dislike, or even hatred for another gay person or for themselves for being gay. This condition is evident in Salma. Salma is a married mother of two whose chance meeting with another woman, Nasreen, results in her reflecting on her past relationship and her alternate sexual preference. Salma is a lesbian and has had a previous relationship with another woman prior to her marriage.

Salma finds a connection to Nasreen as she views Nasreen to be someone she could have been had her circumstances been different. That is probably the reason why she decides to open up about her past relationship with another woman and how she had to put away all her feelings for another woman due to her family values and upbringing. Upon opening up to Nasreen about being a lesbian herself, it can be garnered that Salma is unable to truly accept her own feelings and eventually denies Raj, her past lover who is a woman, from a full-fledged intimate relationship. She retorts that Raj was "more lesbian" than her and that she was not sure if she was ever "really all that" - lesbian - herself. (Doctor 2007: 217). She continuously denies her true idenity and leaves the people around her confused with her true self. Her ability to remain in a heterosexual marriage is also a clear indication of her denial to accept her truth. Interestingly, she does not display any confusion or delusion about her affiliation but seems to present a strong disregard for it which depicts a strong manifestation of horizontal oppression as delineated by Meyer and Dean (1998).

She manifests an evident dislike and disgust for her inclination and also for her brother whom she believes could be subscribing to an alternate sexual preference as well. The excerpt below clearly describes her horizontal oppression:

"Not for the first time, she wonders if Rahim knew all along the nature of her relationship with Raj. She's often wondered if Rahim was that way too. 
That way, deviant, unnatural, not normal. The evidence stacked up, although being the private person he is, Rahim had never left many clues for Salma to find. Somehow, he expertly avoided all pressures to be married, but then being male, he was never pressured the way Salma was. But still, there are his unmasculine habits - being unskilled at sports, but gifted in the kitchen and good with children - that made him awkward as a teenager but now regarded as a devoted son and uncle." (Doctor 2007: 240).

For a gay person herself, Salma assumes and believes that her inclination is unnatural and deviant and anyone else in a similar circumstance, even her very own brother, is also inclined to an abnormal and ultimately erroneous and immoral disposition. Her inner thoughts display an almost vindictive dislike for her brother for both most probably being gay and more so for his ability to perhaps 'get away' with it because he is a man and men are able to make their own decisions in her native society and upbringing. She also laments about how his 'unmasculine' behaviours paint a better picture of him rather than actually landing him in any sort of trouble as it would her. While her comments represent her discriminative thoughts about anyone gay including herself, it also relays her obvious dislike of her brother being able to get away with being himself. She, as a woman, cannot afford such a luxury when it is only right that she is married off and of course any kind of affiliation that is non-normative is completely forbidden.

Another manifestation of internalized homophobia as delineated by Meyer and Dean (1998) is secrecy and concealment whereby the LGBTQ individual hides his or her inclination from people around them out of fear of stigma. Similarly, Salma too was one who kept her relationship with Raj a secret. Her secrecy and concealment can be seen in the excerpt below:

"It must have been hard to keep it a secret, you know, to sneak around?" Nasreen says in a stage-whisper.

"Well, I don't know how hard it was to keep it a secret. We just knew we had to. I didn't even tell my best friend, Ritu. Although she may have suspected something. She disliked Raj because Raj was sort of known to be that way. She was sort of mannish... and people spread rumours - you know how people can be about things like that."

"Sounds like Raj was butch. People always give gender-nonconforming queers the hardest time. It's so stupid." (Doctor 2007: 217)

Given her circumstances then, Salma believed that secrecy and concealment was the best way to go about her inclination and this clandestine behaviour persisted well into her marriage and decades of her life.

Therefore, the manifestations of internalized homophobia as explicated by Meyer and Dean (1998)'s framework are valid and apparent in the LGBTQ character of this book i.e. Salma. Manifestations of horizontal oppression and secrecy and concealment are depictions of Salma's internalized homophobia. Meyer (2003: 678) explains that "minority identity [which refers to the LGBTQ as a minority group] is linked to a variety of stress processes; some LGB people, 
for example, may be vigilant in interactions with others (expectations of rejection), hide their identity for fear of harm (concealment), or internalize stigma (internalized homophobia)." Displaying these manifestations are indicative of the presence of internalized homophobia. Salma had continually concealed her true self and only opened up to Nasreen as she felt a connection and safety net as Nasreen was a lesbian herself.

In addressing the challenges to the construction of a rooted cosmopolitan identity, it is pertinent that the discussion highlights the most plausible reasons for the manifestation of internalized homophobia in the LGBTQ character of this novel. Salma's manifestations of horizontal oppression and secrecy and concealment have stemmed from her familial values and cultural affiliations from her upbringing. Internalized homophobia is not an individual trait as much as it is a reflection of an interaction between an LGBTQ individual and their environment (Frost and Meyer 2009; Russell and Bohan 2006). The findings aforementioned are key in understanding why internalized homophobia develops in an LGBTQ individual whereby one's upbringing and family values as well as views of the surrounding society in general have a significant impact on how an LGBTQ individual perceives themselves and their inclinations.

Barnes and Meyer (2012: 513) note in their empirical research that they had "predicted that the social environments in non-affirming religious settings, which promote homophobia, induce internalized homophobia." This sentiment can be especially true for individuals who find a strong sense of belonging in their religious affiliation only to be turned away. While there is no evident indication that her parents' and family's religious beliefs were in any way discriminative of the LGBTQ per se, cultural conventions of the family were strong enough to negate any alternate sexual preferences. Salma herself knew this and therefore, she chose to hide away her true feelings and desires while trying to keep her parents at bay.

Her parents had wanted her to get married but Salma had done her very best for a long time to placate them by meeting suitors but then rejecting them completely.

Each year since completing her A-levels, Salma had become more vocal about her anti-marriage sentiments and she loved having this familiar argument with Ritu. It made her feel sure about herself, articulate, progressive. In truth, Ritu was an easier target for her diatribes than her own nagging parents. With them, she was more passive. She went along with their plans to meet this cousin's cousin or that uncle's friend's son. She got dressed up in her best clothes, made small talk and then one by one rejected each suitor. This strategy, although labour intensive, was easier than being honest with her parents. They would never understand her views. Rather than trying to convince them, she hoped to tire them out until they finally gave up on her. (Doctor 2007: 173)

Salma attempted her absolute best to maintain a strategic distance from marriage totally at the outset. In doing as such, she picked the way of secrecy and concealment as is showed in characters with internalized homophobia. She did not reveal 
her true desires considering the idea that her parents would not comprehend or acknowledge her for what her identity is. So she shrouded her cogitations and wants and obliged their arrangements to find her a suitor. Salma herself believed that her parents would never accept her true desires and inclinations and believed that she was unnatural and immoral to want a relationship with another woman. Salma ruminated on the outcome of her relationship being disclosed to her parents. She concluded that they:

[...] would have wondered what had become of their shameful daughter, questioned where they had gone wrong, and ultimately they would have blamed Raj, forbade Salma to see her ever again and forced a marriage upon her. Would Salma have blamed them for their judgements? [...] there were moments during which her private thoughts were interrupted by worries that she was somehow abnormal, if not immoral. (Doctor 2007: 246)

It was her worries over her parents' responses, fuelled by the heterosexist beliefs of society that established that her relationship with someone of the same sex would never work and that brought up issues of abnormality and inadequacy in her. Keeping in mind the sentiments of the society around her and the desires of her family induced in Salma the stigma that is internalized homophobia from which she thusly shaped a 'functional' side that distinguished her relationship with another lady as inaccurate and inadmissible.

Salma cannot seem to accomplish some certainty and faith in her own actual self in spite of currently being in a cosmopolitan space where she can express her true desires and inclinations to someone else without clandestineness or camouflage, something which she never at any point had the certainty to do previously. Subsequent to seeing the kinship among Nasreen and Asha, the two lesbians and good friends who she encounters while teaching them Gujarati, and the simplicity at which they had the option to just live their lives being free and unchained of heterosexist shackles, Salma opens up to Nasreen about her relationship with another lady before she had gotten married. But despite opening up, she still is unable to accept her affiliation as normal and acceptable.

One could contend that being a married woman with two little girls could be an obstruction to accepting her interest and inclination toward women. But, Salma does act upon her senses and kisses Nasreen out of the blue.

"My life hasn't allowed much time to feel since we came here. Until recently, I only had the time to see myself as Shaffiq's wife, the girls' mother. That's it. Until I met you and Asha, I had almost given up on myself being a teacher, even." (Doctor 2007: 299)

Salma's experiences with Nasreen and Asha is an acknowledgment that in the cosmopolitan culture she is currently part of, individuals like her who subscribe to alternate sexual preferences are as acknowledged, free, typical, and accepted as any other standard-acclimating person. Even so, the long periods of secrecy and concealment that Salma had acclimatized to had negatively affected her so much 
so that despite being in a cosmopolitan space, her manifestations of internalized homophobia fuelled by her own upbringing and values have obstructed her from attaining a rooted cosmopolitan identity.

The more interesting observation to be proffered is that Salma presents a certain level of hypocrisy whereby while she remains rooted in her culture and beliefs, she denies the acceptance of her own alternate sexual preference. This denial is a negation of her ability to inculcate the understanding of Appiah's first strand which requires a rooted cosmopolitan to be fair and accept people of various affiliations even those that are considered to be non-normative or nonconforming. In a somewhat binary opposition, Shaffiq is a character that can be advocated as a rooted cosmopolitan with a rooted cosmopolitan identity.

While at first he struggles with the idea that his Indian friend was going to marry a Canadian woman, he slowly grows into accepting the cultural differences from his own upbringing and family as well native society ideals. In his own ways, Shaffiq is able to overcome his own misgivings and embrace the new affiliations presented to him as a migrant. While his reaction to his wife being a lesbian remains more of a mystery, he never shows any outward disgust to another person, such as Nasreen, being gay. One could assume that he shows no particular disdain for the LGBTQ but his wife being one would be a cause to wonder as he of course is married to her and was never privy nor was there any indication that she was a lesbian. Therefore, Salma's inability to fulfil Appiah's first strand of rooted cosmopolitanism is the exact reason why she was unable to be deemed a rooted cosmopolitan.

\section{Conclusion}

Contemporary cosmopolitans believe that every person has global stature as the ultimate unit of moral concern and is therefore entitled to equal respect and consideration no matter what her citizenship status or other affiliations happen to be (Brock, 2013). Concomitantly, Appiah's concept of rooted cosmopolitan echoes the aforementioned ideas while also highlighting the importance of championing one's own cultural affiliations while inculcating values of universal concern pluralism. This paper sought to dissect the challenges presented to an LGBTQ character of a contemporary Indian diasporic novel in becoming a rooted cosmopolitan.

In order to achieve the objective mentioned, it was first vital to explicate and demarcate the rooted cosmopolitan ideals which enables the migrant characters to achieve a rooted cosmopolitan identity. The cosmopolitan space is representative of an accepting environment where even people of alternate gender construction or sexual preference have reason to feel free and accepted as well as being devoid of prejudice. The concern here is that despite having that accommodating climate, the LGBTQ character, Salma, was unable to construct a rooted cosmopolitan identity.

The main premise of this paper is to postulate and expound on internalized homophobia and its manifestations resulting in the obstruction of the LGBTQ 
character's ability to construct a rooted cosmopolitan identity. Salma's horizontal oppression, secrecy and concealment developed over the years are a consequence of the familial values and upbringing. The ensuing pressures of conforming to familial expectations and relationships make up a huge part of her life. Therefore, Salma's predicament is mainly resultant from her family background and the cultural conventions of her motherland. Herein lies the inability to become a rooted cosmopolitan whereby it is her familial beliefs and cultural affiliations from the motherland that has encumbered her from being a rooted cosmopolitan and embracing the rooted cosmopolitan ideals of being in the migrant nation. This is a direct impediment to the rooted cosmopolitan ideals of Appiah (2006) that advocate being accepting and prejudice-free of every member of the global village and yet remaining true to one's beliefs and culture.

Hence, the LGBTQ character, Salma, in the novel Stealing Nasreen (2007) by Farzana Doctor is unable to construct a rooted cosmopolitan identity as a result of internalized homophobia. One's family values, beliefs, and upbringing are a huge representation of one's cultural affiliations and identity. While a rooted cosmopolitan celebrates these cultural affiliations in a new host country sought through migration, the same cultural affiliations are also a hindrance that results in the inability of constructing a true rooted cosmopolitan identity. While fulfilling Appiah's second strand of remaining rooted in her family values, belief, and culture, Salma also develops internalized homophobia that hinders her from fulfilling the first strand of acceptance and non-prejudicial thoughts. While she may not have failed entirely in inculcating a rooted cosmopolitan identity, it is clear that internalized homophobia has played a significant role in hindering her from attaining a true rooted cosmopolitan identity.

Not every premodern society made its elite hereditary, as the eunuchs who ran the Ottoman empire would have attested. But it is only in the modern age that the idea has grown that every one of us begins life with an equal entitlement to respect, an entitlement that we may, perhaps, lose through misbehavior but that remains with us otherwise for all our lives. This idea of the equal dignity of all persons can be cashed out in different ways, but it undergirds the attachment to a democracy of unlimited franchise; the renunciation of sexism and racism and heterosexism; the respect for the autonomy of individuals, which resists the state's desire to fit us to someone else's conception of what is good for us; and the notion of human rights -rights possessed by human beings as such - that is at the heart of liberal theory. It would be wrong however to conflate cosmopolitanism and humanism because cosmopolitanism is not just the feeling that everybody matters. For the cosmopolitan also celebrates the fact that there are different local human ways of being; humanism, by contrast, is consistent with the desire for global homogeneity. (Appiah 1997: 621)

Appiah's words provide a salient observation for Salma's situation. While the idea of rooted cosmopolitanism celebrates the renunciation of heterosexism and advocates for equal rights for all persons, the development of internalized 
homophobia in Salma ultimately deters her from adopting a true rooted cosmopolitan identity. Appiah himself advocates for doing away with the concept of boxing people into someone else's idea of what is right or appropriate while also allowing themselves to celebrate their origin and culture. The quintessence of Appiah's rooted cosmopolitanism lies in the championing of equal rights and autonomy for all subcultures within a society while encouraging the retention of one's authentic cultural affiliations. It is certainly imperative, in the case of Salma for example, that Appiah's two strands of rooted cosmopolitanism are mitigated judiciously to ensure that one commits no injustice to others and more importantly to one's own self.

\section{References}

Appiah, Kwame Anthony (1997) Cosmopolitan patriots. Critical inquiry 23 (3), 617-639. https://doi.org/10.1086/448846.

Appiah, Kwame Anthony (2006) Cosmopolitanism: Ethics in a world of strangers (issues of our time). New York, London: WW Norton \& Company.

Barnes, David. M. and Ilan H. Meyer (2012) Religious affiliation, internalized homophobia, and mental health in lesbians, gay men, and bisexuals. American Journal of Orthopsychiatry 82(4), 505.

Brock, Gillian (2013) Cosmopolitanism versus Non-cosmopolitanism: Critiques, Defenses, Reconceptualizations. Oxford: Oxford University Press.

Doctor, Farzana (2007) Stealing Nasreen: A Novel. Canada: Inanna Publications \& Education Incorporated.

Frost, David M. and Ilan H. Meyer (2009) Internalized homophobia and relationship quality among lesbians, gay men, and bisexuals. Journal of Counseling Psychology 56 (1), 97.

Kymlicka, Will and Kathryn Walker (2012) Rooted Cosmopolitanism: Canada and the World. Vancouver: UBC Press.

Maciel, Robert (2014) Rooted Cosmopolitanism. (Unpublished doctoral dissertation) Canada: The University of Western Ontario.

Meyer, Ilan H. (2003) Prejudice, social stress, and mental health in lesbian, gay, and bisexual populations: conceptual issues and research evidence. Psychological bulletin 129 (5), 674 .

Meyer, Ilan H. and Laura Dean (1998) Internalized homophobia, intimacy, and sexual behaviour among gay and bisexual men. In: Gregory M. Herek (ed.) Stigma and Sexual Orientation: Understanding Prejudice against Lesbians, Gay Men, and Bisexuals. California: Sage Publications, 160-186.

Nussbaum, Martha (2010) Patriotism and cosmopolitanism. In: Brown, Garrett Wallace and David Held (eds.) The Cosmopolitanism Reader. Cambridge: Polity Press, 155-162.

Razack, Sherene (2004) Dark Threats and White Knights: The Somalia Affair, Peacekeeping, and the New Imperialism. Toronto: University of Toronto Press.

Russell, Glenda M. and Janis S. Bohan (2006) The case of internalized homophobia: Theory and/as practice. Theory E $\mathcal{F}^{2}$ Psychology 16 (3), 343-366.

Thobani, Sunera (2007) Exalted Subjects: Studies in the Making of Race and Nation in Canada. Toronto: University of Toronto Press. 
Shobana Jeyasingam is a doctoral candidate currently affiliated with the Faculty of Modern Languages and Communication in Universiti Putra Malaysia. Her specialization will be in the field of English Literature with a specific interest in fictional works of contemporary writers of the Indian diaspora. Her current interest of study is in the concept of cosmopolitanism and perspectives of cosmopolitanism among marginalized subcultures such as the LGBTQ community.

Address: Shobana Jeyasingam, Faculty of Modern Languages and Communication, Universiti Putra Malaysia, Jalan Upm, 43400 Serdang, Selangor, Malaysia. [email: shobana. jeyasingam@gmail.com]

Manimangai Mani is a Senior Lecturer in the Department of English in the Faculty of Modern Languages and Communication, Universiti Putra Malaysia. Her specialization is in the field of English Literature with specific interests in African and Caribbean Literature, Postcolonial Literature, Indian Subcontinent Literature, and Comparative Literature.

Address: Manimangai Mani, Faculty of Modern Languages and Communication, Universiti Putra Malaysia, Jalan Upm, 43400 Serdang, Selangor, Malaysia. [email: manimangai@upm. edu.my]

Rosli Talif is an Associate Professor in the Department of English in the Faculty of Modern Languages and Communication, Universiti Putra Malaysia. His specialization is in the field of English Studies with specific interests in Literature in ESL and Reading, Literature and Gender, and Language Planning and Policy.

Address: Rosli Talif, Faculty of Modern Languages and Communication, Universiti Putra Malaysia, Jalan Upm, 43400 Serdang, Selangor, Malaysia. [email: rtalif@upm.edu.my]

Mohammad Ewan Awang is a Senior Lecturer in the Department of English in the Faculty of Modern Languages and Communication, Universiti Putra Malaysia. His specialization is in the field of English Literature with specific interests in English Literature, Literary Theory and Criticism, Space and Place in Literature.

Address: Mohammad Ewan Awang, Faculty of Modern Languages and Communication, Universiti Putra Malaysia, Jalan Upm, 43400 Serdang, Selangor, Malaysia. [email: ewan@ upm.edu.my] 